\title{
Study on physico-chemical analysis of ghee
}

\author{
Amit Kumar*1, S. K. Goyal ${ }^{2}$, Munesh ${ }^{1}$, Vishal Kumar ${ }^{3}$ and Lalit Kumar ${ }^{3}$ \\ ${ }^{1}$ Deptt. of Food Science \& Tech., Faculty of Science, S.V. University, Gajraula (U.P.) \\ ${ }^{2}$ KVK, Institute of Agril. Scs., RGSC, BHU, Barkachha, Mirzapur (U.P.) \\ ${ }^{3}$ Deptt. of Agril. Engg. SVP Univ. of Agriculture \& Technology, Meerut (U.P.)
}

*E-mail: amitkumarfoodtech@gmail.com, sunil.svbp@gmail.com

\begin{abstract}
The ghee is adulterated on large scale in India. The most common types of adulterants used are vegetable oils and animal fats. The detection of animal fat in ghee is difficult as the mixture has more or less the same physical and chemical characteristics. Any type of adulteration in ghee samples bring about the changes in the physical and chemical properties of ghee. A study was conducted to determine the physico-chemical qualities of ghee samples sold in Meerut City. The samples of ghee were also tested to check whether it meets the specifications or not. The samples were collected from three locations of local market. The moisture or volatile content of sample $1 \& 2$ were $(0.24$ and $0.27 \%)$ within the range, while, it was exceeded for sample $3(0.40 \%)$. FFA value of sample $1 \& 3$ were $(1.26$ and $1.33 \%$ ) confirm the standard range, whereas it was more than standard specification (1.6\%) for sample 2. Polenske value of sample 1 was (0.63), it was also within the standard range, while it was more than standard for sample $2 \& 3$ (2.5 \& 1.06). Reichert meissl value for sample $1 \& 2$ (28 and 29) were confirm the standard specification. While, the RM value of sample 3 (40.2) were exceeded. The sample-1 was found best for moisture or volatile content, FFA, Polenske value and RM value present as per the standard specification. Preparation of ghee should be well monitored and chemical analysis of ghee also should be done periodically for maintaining the quality of ghee by the manufacturers.
\end{abstract}

Keywords: Ghee, Physico-chemical qualities, Free fatty acid, Reichert-meissl (RM) value and Polenske value.

Paper Cited: Kumar, A., Goyal, S.K., Munesh., Kumar, V. And Kumar, L. (2016). Study of physic-chemical analysis of ghee. South Asian Journal of Food Technology and Environment, 2(3\&4): 448-451.

\section{Introduction}

The word ghee is evolved from Sanskrit word ghruta. Ghee is a common Indian name for clarified butter fat. The origin of ghee making probably lies far beyond recorded history. The word itself stems from the old Sanskrit 'ghr' which means bright or to make bright. When sprinkled on fire, butterfat enhanced its brightness merged with cause. Butter fat was later christened ghruta, which evolved into ghee (Dhurvey et al., 2012). Ghee is important part of human diet. It is the most important ingredient in food and it is rich source of dietary energy and contains high calorific value. The Ghee contains certain acids which are very important and essential for the human beings. They are vehicle for the fat soluble vitamins. The supply of ghee is less in market for its high demand. The gaps of availability and shortage leads to several malpractice and adulteration (Jariwala, 2014).

According to PFA (2009) "Ghee" means the pure clarified fat derived solely from milk or curd or from desi (cooking) butter or from cream to which no colouring matter or preservative has been added. Ghee is complex lipids of glycerides, free fatty acids, phospholipids, sterols, sterol esters, fat soluble vitamins, carbonyls, hydrocarbons and carotenoids (cow ghee). Ghee also contains 
traces of iron and calcium. It contains moisture. The major constituent of ghee is glycerides which constitute $98 \%$ of total material in ghee and rest $2 \%$ consist of sterols most commonly cholesterol occur to the extent of about $0.5 \%$. Ghee is most commonly prepared in India as home industry (Kumar et al., 2010). Ghee is usually prepared by four methods: Desi Method, Creamy Butter method, Direct Cream Method and Presatisfication Method. The desi method is most commonly used of four methods for the preparation. The quality of ghee prepared by any of this method depends upon the quality of milk, cream, dahi (Curd), butter, method of preparation, temperature, conditions of storage and type of animal feed. These factors in turn will help in determining physicochemical properties of ghee. The quality of ghee is determined by three parameters: Peroxide value, Flavour and Acidity. The quality of ghee on storage has been measured by acid and peroxide value. The temperature of clarification is most important factors that control the intensity of flavour of ghee. Ghee prepared at $120^{\circ} \mathrm{C}$ or above has intense flavour which is usually referred as cooked or burnt ghee while prepared around $110^{\circ} \mathrm{C}$ has somewhat mild flavour. Flavour retains longer if ghee contains $1 \% \mathrm{NaCl}$. The flavour of ghee is affected by the acidity of cream or butter. Cream butter having acidity of $0.15-0.25 \%$ as in ripened cream butter produces a ghee with most acceptable flavor (AGMARK, 1988). Rate of deterioration of ghee is less prepared from unripened butter as compare to ghee prepared from ripened butter.

Ghee, widely considered as the Indian name for clarified butterfat, is usually prepared from cow milk or buffalo milk or combination thereof. It is the most widely used milk product in the Indian sub-continent and is considered as the supreme cooking and frying medium. In its table use, ghee is served in hot melted form and used for garnishing rice or spreading lightly on chapattis. Ghee contributes significantly towards nourishment of people of all age groups. It is a good source of fat-soluble vitamins (A, D, E and K) and essential fatty acids (Rangappa and Achaya, 1974). Ghee contains about $0.2-0.4 \%$ cholesterol (Nath et al., 1996). In ghee, cholesterol is present in both free as well as in esterified form (Bindal and Jain, 1973).

The ghee is adulterated on large scale in India. The most common types of adulterants used are vegetable oils and animal fats. The detection of animal fat in ghee is difficult as the mixture has more or less the same physical and chemical characteristics. The adulterants like starch (Potato), sesame oil, dyes, synthetic colours, vegetable fat, lard and wax. Sometimes the rancid ghee is also mixed with the fresh ghee and sold in the market. Any type of adulteration in ghee samples bring about the changes in the physical and chemical properties of ghee (Jariwala, 2014).

Therefore, in this study the attempts were made to assess the physico-chemical properties of Ghee samples collected from Meerut City.

\section{Materials and Methods}

The samples were collected in $100 \mathrm{~g}$ sterilized glass jars from three locations of Meerut City. Then samples were brought to the laboratory for further analysis. Test performed for the following quality of ghee:

\section{Physical Test:}

1. Colour \& appearance,

2. Body \& texture, and

3. Flavour

\section{Chemical Test:}

1. Moisture or volatile content

2. FFA (Free fatty acid) per cent as oleic Acid

3. Reichert Meissl (RM) Value

4. Polenske value

5. Baudouin Test

6. Mineral oil Test (Holders Test) 
All physical and chemical tests were determined as per method described by SP: 18 (1981) with three replications.

\section{Result and Discussion}

\section{Physical tests}

Color \& Appearance: The color of all samples was light yellowish and uniform. When melted it was clear, transparent and free from sediments.
Body \& Texture: The body and texture of samples was good. The grains were large in size and uniform.

Flavor: The flavour of all samples was natural pleasant, slightly cooked and free from rancidity or any other objectionable flavor.

\section{Chemical Test}

The data obtained during course of investigation for chemical analysis carried with different samples of ghee are given in Table 1.

Table-1: Physico-chemical analysis of ghee samples

\begin{tabular}{|c|l|c|c|c|c|}
\hline S. No. & \multicolumn{1}{|c|}{ Parameter } & High value & Low value & Mean & Standard value \\
\hline 1 & Moisture Content (\%) & 0.40 & 0.20 & 0.30 & 0.30 \\
\hline 2 & FFA (Oleic Acid) & 1.16 & 1.23 & 1.42 & 1.40 \\
\hline 3 & Polenske Value & 2.50 & 0.63 & 1.56 & 1.00 \\
\hline 4 & Reichert-Meissl & 40.20 & 28.00 & 34.10 & $28-35$ \\
\hline
\end{tabular}

\section{Moisture content (\%)}

The standard value for the moisture per cent is 0.3 and the average value of sample 1 was 0.24 which was within the range (Table 1). In sample 2 the moisture per cent was 0.27 which was also within the range, whereas moisture per cent of sample 3 was 0.40 which was out of range.

\section{Free Fatty Acid (FFA, \%)}

The value for free fatty acid (as oleic Acid) of samples of ghee is presented in Table 1. The target value for free fatty acid should not be more than 1.4. The average value for free fatty acid of the samples 1 and 3 were $1.26 \%$ and $1.33 \%$, respectively, which were within the range. While, FFA value of the sample 2 was 1.6 . It was exceeded $(0.2 \%)$ from the standard value.

\section{Polenske value}

The polenske value in different samples of ghee is shown in Table 1. The target value for polenske value should not be more than 1 . The average polenske value of sample 1 was found 0.63 , it was within the standard specification range. While, the polenske value of sample 2 and 3 was 2.5 and 1.06 , respectively. These values were more than standard specification value.

\section{Reichert meissl (RM) value}

The average Reichert meissl value of different samples of ghee was given in Table 1. The target value of RM should not less than 28 and more than 35 . The average value of sample 1 and 2 were found 28 and 29, which meet the required standard value. Whereas, RM value of sample 3 (40.2) was found out of the standard range.

\section{Baudouin test}

During the analysis the Baudouin test and mineral oil test the results were negative for all the samples.

\section{Conclusion}

All samples were found upto the mark for physical tests. The data obtained from the chemical analysis for moisture or volatile content and Reichert Meissl, sample 1 \& 2 were within the standard range. While, for free fatty acid and Polenske value the data obtained from sample $1 \& 3$ were fit as per the standard specification. Results of Baudouin test were negative for all the three samples of ghee. Thus, it clearly indicates that sample-1 was found best for moisture or volatile content, FFA, Polenske value and RM value 
present as per the standard specification. Hence, it can be concluded that preparation of ghee should be well monitored and chemical analysis of ghee also should be done periodically for maintaining the quality of ghee.

\section{References}

1. AGMARK (1988). Ghee Grading and Marketing Rules, 1938 (as amended in 1988). New Delhi: Government of India, Ministry of Food and Agriculture, Department of Agriculture.

2. Bindal, M.P. and Jain, M.K. (1973). Studies on cholesterol content of cow and buffalo ghee. Indian Journal of Animal Science, 43: 918924.

3. Dhurvey, Y.R., Kawtikwar, P.S. and Sakarkar, D.M. (2012). Evaluation of physic-chemical properties of cow ghee before and after hydrogenation. International Journal of ChemTech Research, 4(1): 185-189.

4. Jariwala, K.N. (2014). Analytical techniques for the assessment of Physico-chemical properties of ghee.
Indian Journal of Applied Research, (4)6: 216-217.

5. Kumar, M.; Sharma, V.; Lal, D.; Kumar, A. and Seth, R. (2010). A comparison of the physico-chemical properties of low-cholesterol ghee with standard ghee from cow and buffalo creams. International Journal of Dairy Technology, 63(2): 251-255.

6. Nath, B.S.; Usha, M.A. and Murthy, M.K.R. (1996). Effect of deep-frying on cholesterol oxidation in ghee. Journal of Food Science and Technology, 33: 425426.

7. PFA (2009). Prevention of Food Adulteration Act, 1955 (as amended). Delhi: Universal Law Publishing Co. Pvt. Ltd., Ansal's Dilskhush of Estate.

8. Rangappa, K.S. and Achaya, K.T. (1974). Indian Dairy Products. Mysore City, India: Asia Publishing House.

9. SP:18 (1981). Handbook of Food Analysis. Part XI Dairy Products. Manak Bhawan, New Delhi, Bureau of Indian Standards.

\section{Received: June 2016， Revised: July 2016， Accepted: September 2016}

